OPEN ACCESS

Edited by:

Yoram Chisik,

University of Madeira, Portugal

Reviewed by:

Carlos Vaz De Carvalho,

Polytechnic Institute of Porto, Portugal

Tonguc Ibrahim Sezen,

Teesside University, United Kingdom

*Correspondence:

Micael Sousa

micaelssousa@gmail.com

Specialty section:

This article was submitted to

Human-Media Interaction,

a section of the journa

Frontiers in Computer Science

Received: 07 April 2020

Accepted: 22 July 2020

Published: 04 September 2020

Citation:

Sousa M (2020) A Planning Game

Over a Map: Playing Cards and

Moving Bits to Collaboratively Plan a

City. Front. Comput. Sci. 2:37.

doi: 10.3389/fcomp.2020.00037

\section{A Planning Game Over a Map: Playing Cards and Moving Bits to Collaboratively Plan a City}

\author{
Micael Sousa* \\ CITTA, Department of Civil Engineering, University of Coimbra, Coimbra, Portugal
}

Rational systemic planning and collaborative planning seem to be two conflicting approaches in spatial planning practice and research. However, some authors are trying to make them compliant through new approaches that are more human centered. Applying games to planning processes can be one of many solutions to consider. This article describes the process of developing an analog game session and the first test of this serious board game approach. This game approach began with modern board game design elements as a starting design base and was adapted for further developments in game-based planning processes, following the methods of serious games through the adaptation of the design, play, experience framework. The purpose of this game session is to create a simple and flexible tool to train students and future planners for the use of games in the development of collaborative urban planning processes, contributing to filling the gap created by the absence of simple and flexible games to use in daily planning practices.

Keywords: collaborative planning, serious games, board games, tabletop games, urban games

\section{INTRODUCTION}

Creating a game is not an easy process. Developing a serious game to apply to educational purposes or to be used as a support for participative and collaborative planning processes, in which budget, time constraints, or even expert skills are lacking (Ampatzidou et al., 2018), can be even harder (Crookall, 2010). The collaborative planning approach in the spatial planning field of research aims to include as many stakeholders as possible in the processes to deliver better plans suited to individual and community needs (Healey, 1997). A long debate pitting rational systemic planning in opposition to collaborative planning seems to be fading as the main authors try to establish some bridges between them (Innes and Booher, 2018).

The intent of this research is to contribute to developing new game approaches that address this tendency toward integration between rational systemic approaches and collaborative planning ones. This was done through the use of analog tabletop/board games, tested during a practical lecture with civil engineering students in a class on regional and urban planning. The game exercise consisted of two different games that happened in a sequence over the same map of the city. The two games had very different components and game mechanics although they formed a logical sequence and were played over the same map.

The first game was designed to establish some common knowledge and communication among players, which is essential to the start of a collaborative process (Healey, 1997). The second game implemented a concrete planning process, based on a game model, in which players could manipulate the urban environment. 
The main objective of this experiment was to provide an example of a prototype, inspired by commonly known modern board game mechanics, that can serve as a practical implementation for daily use. Planning students, teachers, and practitioners following this approach, supported by the design, play, experience (DPE) framework (Winn, 2009), should be able to use games inspired by these methods for their public participation and collaboration processes.

Analog games were tested in this session because they are easier to construct and adapt while naturally fostering collaboration among users (Zagal et al., 2006; Xu et al., 2011; Rogerson and Gibbs, 2018; Rogerson et al., 2018). These games can fill the gap identified by Ampatzidou et al. (2018), in which planning practitioners recognize the potential of games but say that they do not have the resources and knowledge to use them in their daily work.

\section{METHODOLOGY}

The practical, direct objective of the testing session was to create a flexible and simple game dynamic to apply in a class with a $2 \mathrm{~h}$ duration. The game dynamic considered the importance of game mechanics (Järvinen, 2008; Sicart, 2008) in an approach related to the DPE model used for serious game processes (Winn, 2009), in which the game designer creates a playful dynamic system to generate experiences through the use of game mechanics, considered more broadly. In this game experience, there was the need to do some adaptation related to the analog nature of the game and to the need to include a facilitator.

Although the potential of game mechanics is known for serious games (Michael and Chen, 2006; Dörner et al., 2016), the specific game mechanics present in modern board games are not yet fully explored and established in the literature as the recent work from Engelstein and Shalev (2019) shows. The innovations of modern board games, mostly Eurogames, and their main game mechanic typologies and distinctive game play (Woods, 2012) are yet to be explored for practical usage in academic literature (Sousa and Bernardo, 2019).

The inspiration to conduct this new game approach for a planning game over a map began with the City Game experience, first developed by Tan and Portugali (2012), following the complexity theory, according to which individual agents could collaboratively plan, with minimal rules, a coherent urban design. This game approach was tested during the 18th meeting of AESOP: Games for Cities, and it also employed some notions of money management to create restrictions and force players to collaborate by combining their budgets to build the desired projects.

To go deeper into the simulation dimension, game-design elements from modern board games were used, allowing the building of the game approach dynamic over a satellite map retrieved from Google Maps (www.google.pt/maps) at a scale of 1:2000. The game Spyfall (Ushan, 2014) helped to build a common understanding of the urban territory-in this case, the city of Leiria in Portugal. Then, after this first game, a new game, developed especially for this session, was played over the same map. This second game was inspired by the game mechanics of Town Center (Viard, 2014) and City Game (Tan and Portugali, 2012). This last game pretended to establish a collaborative game approach to plan land uses; transport infrastructures; and the economic balance between public services, employment, housing, commercial activities, and the reduction of pollution and negative social impacts from land-use interactions in the city. The use of a printed Google map allowed the adaptation of the game approach to any given territory.

Before the experiment, a pretest was given to the players, documenting the participants' previous experience with games, serious games, and board games in general. After the game dynamic, including the debriefing, players were asked to document the final game experience. The data gathered in the two inquiries followed the Mayer et al. (2014) framework, mostly addressing the experience during game play, the complexity of the game, game flow, immersion, fun, and satisfaction with the learning and simulation process. The intent of the data collection was to understand the previous experience players had with games and their reaction to the game dynamic of the play dimension of the DPE framework (Winn, 2009) as it was considered in the prototype testing (see Figure 1). The debriefing process followed Lederman's (1992) prescriptions with a facilitator offering an overview of the game play and fostering players' self-analysis and collective understanding of the game experiments.

\section{THE RATIONALITY THROUGH COLLABORATION IN PLANNING}

From a rational, systemic, traditional point of view in planning, planners should deliver planning solutions based on mathematical modeling and previsions about housing, transportation, facilities, and other needs for collective land use (Taylor, 1998). With these given options, politicians should decide according to what they believe is in the public interest. As democracies strengthen and their tendency to be more participative models the lack of shared decision making, including citizens and stakeholders, became unacceptable (Innes and Booher, 2018). The rational approach seems to be incapable of addressing the complexities of contemporary societies, in which indifferent solutions fail to properly address people's needs (Healey, 1997). The way to solve the problems of coexistence in today's multicultural societies that are globalized and with free, active citizens appears to be through direct broad participation and co-creation. Nonetheless, the rational, systematic approach is still essential to provide information and make coherent plans (Allmendinger, 2017) even in collaborative approaches.

Several movements providing alternatives to more participative and collaborative solutions in planning have emerged, mostly since the 1980s (Margerum, 2002). Four main influences can be identified:

- The rational communication premise from Habermas (1981), considering that individual demands could be rational if communicated with equality and truth and based on facts and information. 


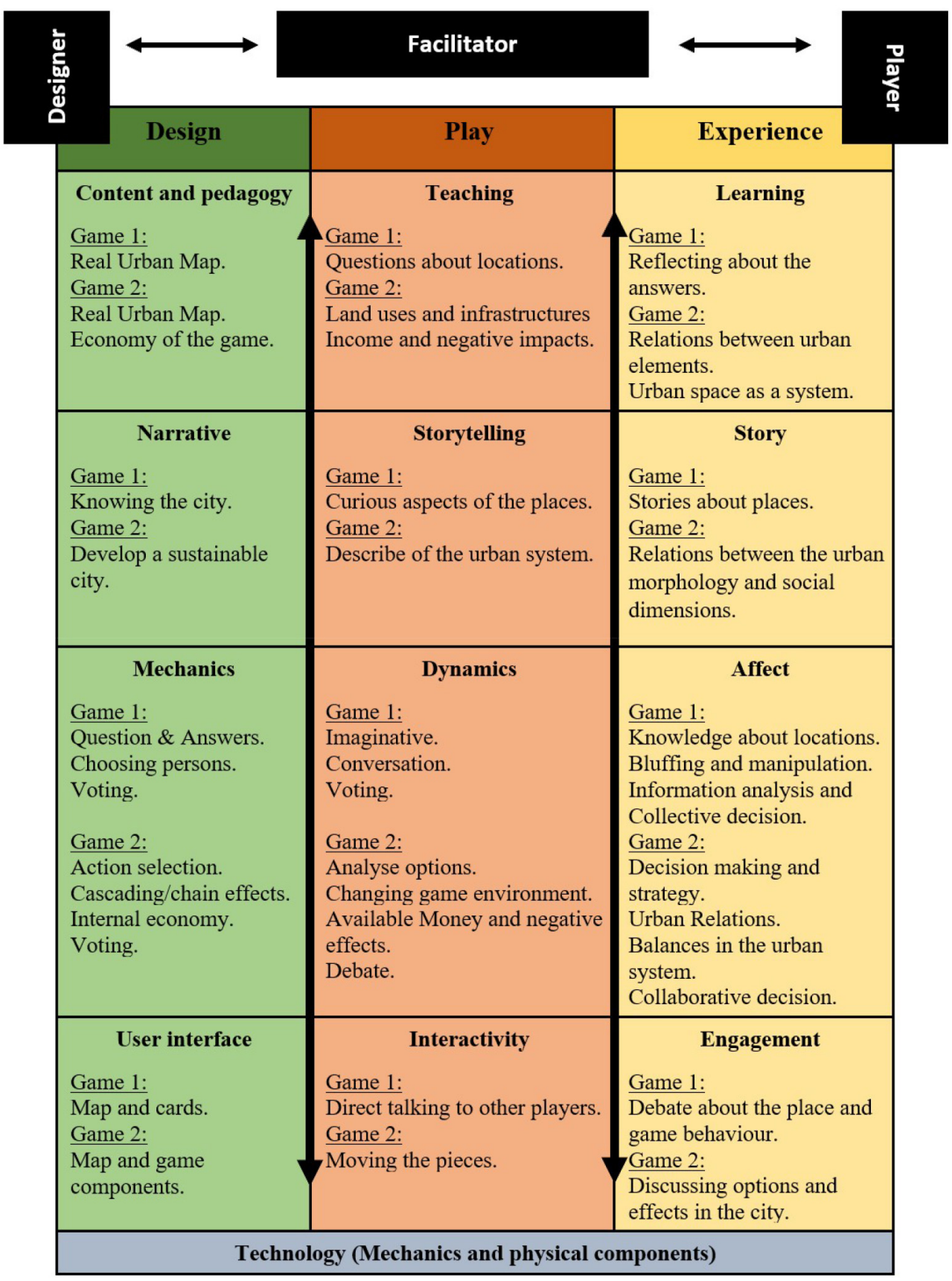

FIGURE 1 | DPE framework adapted to the serious game process of analog games.

- The network society effect in the age of information, which allows citizens to live in parallel societies outside territorial restrictions (Castells, 1996).

- Structuralism, according to Giddens (1984), departing from the notion that agents are influenced by structures and can influence structures to some degree.

- The theory of complexity, following Portugali (2016), approaches include complex systems in which conscious agents plan while participating in incomprehensible and complex collective planning dynamics on higher scales.

These influences inspired many different approaches and testing of new methods. The most common is the collaborative planning process, in which planners act as facilitators, engaging with citizens and stakeholders and providing arenas for free discussion and co-creation, supported by technical knowledge and following some established rules, guidelines, and theoretical influences as 
previously quoted. However, the rational, systemic approach is not compatible with these dynamics based on focus groups, non-linear processes, and other similar methodologies.

Innes and Booher (1996) assume that role-playing games could be a solution to create engaging methods for generating discussion related to the planning topics of a concrete planning problem. Tan (2016) started role-playing in the "generative city game" experiments, concluding that the games required more elements to reach systemic simulation. Resources, real restrictions, and visual modeling helped in the understanding of planning problems and provided more coherent plans through the game-planning approach.

Departing from this acknowledges an alternative approach, which followed modern board game design elements, was tested through a sequence of two games. The first game had minor adaptations to generate a common ground for players, allowing them to know the territory and themselves first. The second game, inspired by cube placement mechanics, created a strategic and fully collaborative simple planning process, generating an urban solution. The game's elements of design and their playable dimensions and experience generation are expressed in Figure 1.

\section{MODERN BOARD GAMES}

Board game design has somehow continued to evolve in the shadow of digital games over recent years. However, some authors consider that we are living in a golden age of board game culture and industry (Booth, 2015; Arnaudo, 2018). Although this is highly questionable, the proliferation of new games and gaming communities all over the world is a fact, which is related to hobby board game design trends, known as modern board games (Sousa and Bernardo, 2019).

Since the 1980s, the board games created and played mainly in Germany defined a new type of product: Eurogames (Woods, 2012). These games updated the design standards in a way that has influenced worldwide game production since the start of the 21st century (Donovan, 2017). Departing from the Eurogame board games' unique elements, new board games, done professionally and innovatively, are influenced by them, also supporting new solutions for serious game purposes. Eurogames provide balanced games that can engage adults with innovative and elegant game mechanics, low luck dependence, controlled gameplay duration, and game systems that can provide medium-weight-complexity models to simulate reality (Woods, 2012). Considering these characteristics, adding to the knowledge that board games provide intrinsic collaborative forms of play (Zagal et al., 2006), the materiality of the game systems provide multiple forms of fun and help the learning process (Xu et al., 2011), and playing a board game is a voluntary act of collective learning, a new game solution was tested in a lecture on regional and urban planning. As Parlett (2018) says, the new games transferred the game dynamics from the board to the players, which suits collaborative planning approaches.
The elegance of the Eurogames' mechanics, which are able to simulate realities while maintaining a playful and engaging dynamic with simplicity and reduced game play (Woods, 2012) is tested in the explored prototype. The exploration of these design features has not yet been fully explored in gaming and the serious gaming literature (Sousa and Bernardo, 2019).

\section{DEVELOPING THE GAME APPROACH EXPERIENCE}

Castronova and Knowles (2015) argue that creating a new game is difficult, and it is easier to use and adapt existing commercial games to generate serious game solutions. Following this suggestion, some well-known board games were tested and adapted to create a planning experiment. In addition, considering that any game can be adapted to be a serious game (Dörner et al., 2016), the selected games were modified to simulate a small urban planning process. Taking into account that a serious game is a game used to deliver other objectives besides fun (Michael and Chen, 2006; Winn, 2009) while maintaining the fun of it, the proposed game approach was constructed to help students in civil engineering from the Polytechnic of Leiria to understand the collaborative planning approach and how it could be implemented through games. To achieve this, two commercial board games were adapted to create the game solution learning tool, which also considered the City Game (Tan and Portugali, 2012) tests.

In a serious game approach, the balance between simulation and playfulness is difficult to achieve, which reinforces the need to profit from established modern board game designs, mostly from Eurogames. Departing from well-tested games, this experiment intended to offer an example for planning practitioners, showing how they can reduce the complexity of developing new game approaches from scratch. It is a pragmatic way to respond to the lack of simple and ready-to-use game tools for planning (Ampatzidou et al., 2018).

The game experiment had a total duration of $2 \mathrm{~h}$. Initially, for $40 \mathrm{~min}$, the students played an adapted version of Spyfall over a Leiria city map, using Post-its to signal the names of the locations. As in the original game, players received random sets of cards that determined their roles. The first game was played in a competitive way although it was played in teams. Instead of the illustrated original cards, the locations and cards were marked with numbers (see Figure 2).

The second game consisted of a city building game with cubes, cardboard, and rope. The game mechanics were inspired by Town Center. However, many modifications were done to simulate different land usage, facilities, green parks, public transport lines, the economy, and pollution. This game was fully cooperative (see Figures 3-5).

The experiment ended with a debriefing process (Lederman, 1992) regarding the planning results, discussing the model created collaboratively by the students during gameplay, starting from a general overview conducted by the facilitator, continuing to the self-evaluation of each player's actions in the game and 


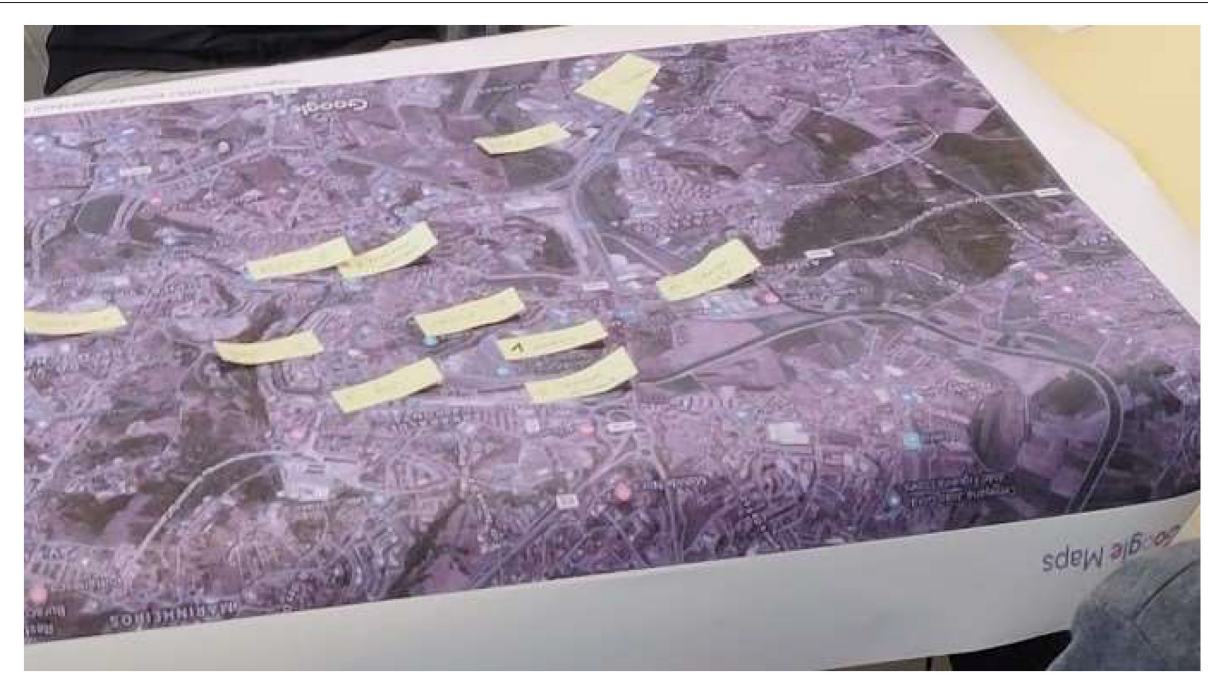

FIGURE 2 | Game play of the first game.

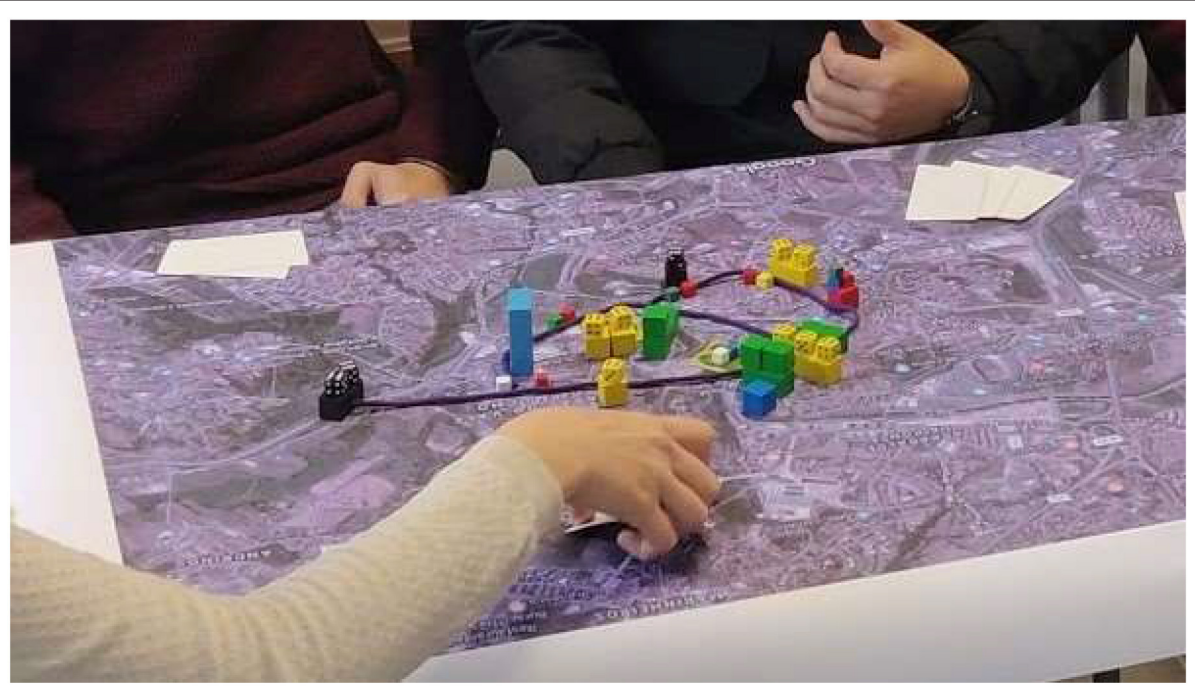

FIGURE 3 | Game play of the second game.

their consequences, and ending in a collaborative conclusion about the game learning outputs. This was done by the game creator, who acted as a facilitator during the entire session, helping players to understand the rules and taking notes to address in the debriefing process. This final step is of great importance because, as Crookall (2010) mentions, the debriefing can be more important than the game itself to establish a serious game.

The games sought to address a real case study and not only an abstract urban landscape. The game design elements from modern board games provided the components and mechanics to establish the game system. The final model, constructed during the second game, should provide a clear understanding of the players' decisions and their interactive effects. However, the real board was missing. The solution rested in using a printed plan from Google Maps with an approximate scale of 1:2000 to serve as the game's common board. This enabled the simulation of land use typologies for the city of Leiria, which was the real city being addressed in the lecture. This scale allowed the use of colored cubes sized approximately $1.5 \mathrm{~cm}$ per edge, which is a component from Town Center and fit the natural block scale of the morphology of the city. It also permitted sticking small Postits $(1 \mathrm{~cm} \times 4 \mathrm{~cm})$ on which were written the names of the places for the first game, related to Spyfall.

\section{GAMES THAT INSPIRED THE APPROACH}

The game session was divided into two separate games that were connected by the main objectives regarding how to develop collaborative approaches and develop a simple, sustainable, 


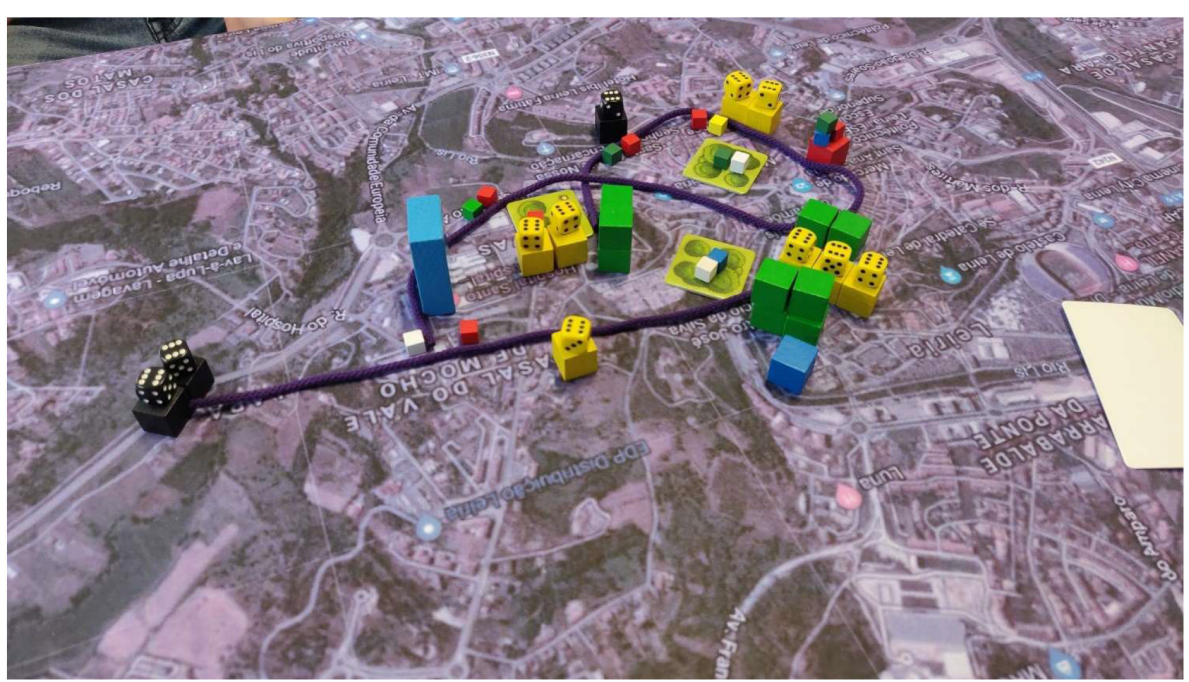

FIGURE 4 | Final visual result from the second game (south view).

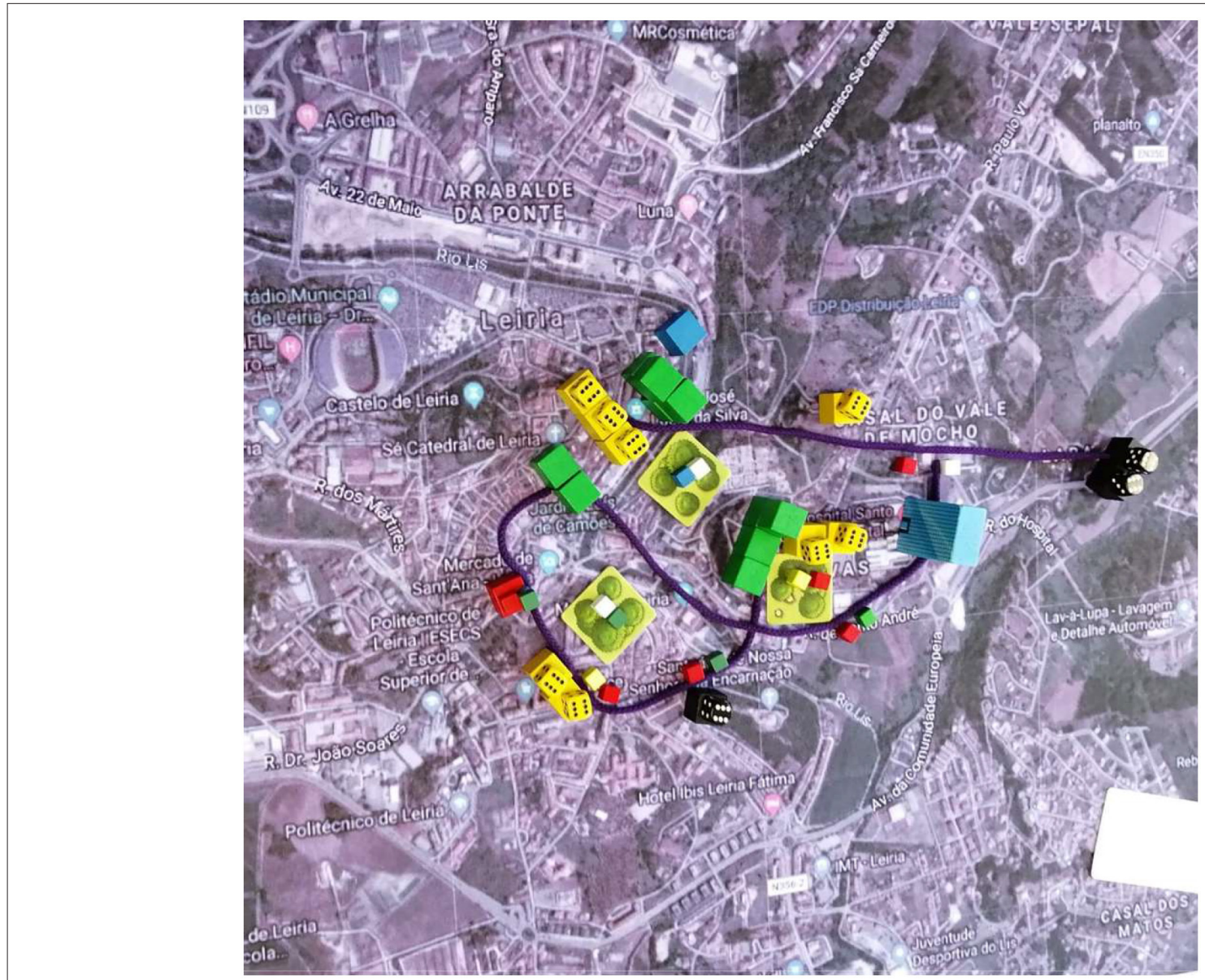

FIGURE 5 | Final visual result from the second game (East View). 
urban model through games. The two games were inspired by several other games, by their mechanics to activate the game system, and their consequent dynamics and experiences related to land knowledge and to the possibility of building a simple, interactive city model. Physical components from several other games were also used to express a meaningful relationship to the reality they intend to represent to players during the game state.

The City Game (Tan and Portugali, 2012) inspired the second game, in particular the freedom to play any game component in turn-based game sequences in which blocking was not allowed. The City Game version tested during the 18th meeting of AESOP, developed by Sara Encarnação and her team from the Nova University of Lisbon, was vital for the definition of the actions table (see Table 1).

Spyfall (Ushan, 2014) consists of a party game of bluffing and deceiving and in which roles are randomly determined in each play. In a game of Spyfall, there are two teams competing: the spy who needs to guess the correct location and the team of the remaining players who know what role they have and ignore the roles of all the other players. The accusing of the spy occurs through voting. The roles are determined by cards that must be kept secret except from the owner. The locations are represented on a large composite map in the center of the table with the same images appearing on the cards representing the player's roles apart from the spy. The adaptation to the serious game experience consisted of using the Google Map of the city of Leiria, first allowing players to choose 12 locations and identifying them with numbers and names marked in Post-its over the map. The numbers on the map matched the cards, which were stacked in small decks. This adaptation maintained the essence of the original game and the fun of it while players created common knowledge about the city. The objective of identifying the spy and the correct location in the city in only $5 \mathrm{~min}$ was done through direct "yes" or "no" questions about each place. To accuse a player of being the spy, a vote needed to be approved by the majority. This created a brief deliberation process. The game used the question mechanics in a deterministic way to generate information players could work with. The absence of random effects within the question mechanics was influenced by Eurogame deterministic designs.
The influence of Town Center (Viard, 2014) in the second game was less than that from Spyfall for the first game although the game mechanic of piling and automatically generating effects from the proximity of neighbor cubes and components was important. This allowed the production of an organically growing simulation model. The big cubes used to simulate land use and facilities came originally from Town Center game except for the hospital and parks. The main mechanic brought from modern board games was the cube placement and the cascading automatic effects in the economy of the game (Engelstein and Shalev, 2019).

The game components in the first game were all handmade. To create the second game, more components were needed. The strings came from String Railways (Hayashi, 2009), the small cubes from Rajas of the Ganges (Brand and Brand, 2017), the dice from Panamax (D'Orey et al., 2014), the green parks from Agricola Farmers of the Moor (Rosenberg, 2018), and the hospital from Suburbia's (Alspach, 2012) first player marker. The coins to simulate the money came from Villagers (Gaarder, 2019).

\section{GENERATING THE CITY MODEL TO PLAN THE CITY THROUGH COLLABORATION}

The first game has already been explained, being very close to the original game of Spyfall, but the second part was very different. This second game, inspired by the City Game and Town Center, was also played over the Google satellite map of Leiria (scale of $1: 2000$ ), having only this component in common with the first one. Players started with 3 money units and played in a sequence of turns, forced to pick a game component that simulated a landuse license in the city, a public facility, a green park, or public transport line to put on the map. Some of these options had monetary costs; others generated revenue to the city common budget as some pollution/negative social impacts (see Table 1).

As can be observed in Table $\mathbf{1}$, there is a lot of simplification in the costs and the effects. The game should be simple so that it can be played almost instantaneously. This was only possible because the facilitator continuously explained the game during the session, clarifying the options and consequences to players.

TABLE 1 | Available actions to players during the second game.

\begin{tabular}{|c|c|c|c|c|}
\hline Actions & $\begin{array}{l}\text { Cost to build } \\
\text { (money units) }\end{array}$ & $\begin{array}{l}\text { Profit generation } \\
\text { (money units) }\end{array}$ & $\begin{array}{c}\text { Pollution/social } \\
\text { negative impacts }\end{array}$ & Available quantity \\
\hline Housing unit (green large cube) & 0 & 0 & +1 & 24 \\
\hline $\begin{array}{l}\text { Commercial/light industry/services unit (green } \\
\text { yellow cube) }\end{array}$ & 0 & $+1 \times$ Surround housing unit & +1 & 8 \\
\hline Heavy industry unit (black large cube) & 0 & $\begin{array}{l}+3+1 \times \text { Surrounding } \\
\text { commercial unit }\end{array}$ & $3+1 \times$ Surrounding unit & 4 \\
\hline Green park unit (cardboard tile) & -4 & 0 & -2 & 4 \\
\hline Police/Fire department unit (red large cube) & -10 & 0 & -3 & 2 \\
\hline School unit (blue large cube) & -20 & 0 & -4 & 2 \\
\hline Hospital unit (suburbia player markers) & -30 & 0 & -6 & 1 \\
\hline Public transport line unit & -5 & 0 & -2 & 4 \\
\hline
\end{tabular}


The values in Table $\mathbf{1}$ were obtained through a spreadsheet, balancing the positive and negative inputs and outputs. In this way, sustainable growth could be achieved, but only if the players balanced their actions, generating money, and choosing actions to reduce the negative effects as soon as they had the required money. Players could not pass because they were always forced to choose something to build. The free actions generated negative impacts, and the ones able to reduce these impacts were expensive, only activating their benefits for the surrounding areas. This city building game exercise was done through collaboration, generating discussion, and debate for each individual decision. When players proposed to use the common city budget to place an expensive facility, a vote was called. The players only had three personal money units, which was not enough to build any of the actions that reduced the negative impacts, essential to achieve the game objectives. To build them, they needed to use the common city budget. The inspiration for this limitation came from the City Game tested during the 18th meeting of AESOP, and the economic systems from Eurogame mechanics (Woods, 2012) were transposed to a spreadsheet.

The pollution and social negative impacts were represented by small cubes, placed near the building that generated them. Colored dice marked the profit from commercial/services and industry cubes and were limited to 6 for each one. This limit established the balance of the game system, determining available components and options to achieve a sustainable city. In this manner, growing the city should be possible while also controlling the piling of the negative cubes throughout gameplay in a clear and representative way. The negative cubes, when absorbed by the positive effects of the facilities, parks, and public transport lines, were placed atop those components to represent that they had exhausted their positive capacity of absorption. The public transport lines made any buildings near and along them to be considered as adjacent.

The game session, considering the two games, is expressed in Figure 1, according to the adaptation of the DPE framework (Winn, 2009) to an analog serious game. In this adaptation, developed by the author of this experiment, there was the need to add the facilitator role because analog serious games have the need to be explained to players and the debriefing part of the experiment needed to be conducted. The technology, in this case, is the mechanics and game components. The DPE adaptation was organized considering the two games in each of the flows:

- learning (content and pedagogy, teaching, and learning);

- storytelling (narrative, storytelling, and story);

- game play (mechanics, dynamics, and affects);

- user experience (user interface, interactivity, and engagement).

From these flows, in a summarized way, the design intended to generate a play experience in which players could learn more about the urban space (first game) and act over it by changing the urban system in a collaborative way to achieve sustainability (second game). The facilitator acted as a mediator between the designer and player, being present during play to observe the experiences. This knowledge plays a major role in supporting the debriefing process.
TABLE 2 | Gaming preferences from players.

\begin{tabular}{lccccc}
\hline $\begin{array}{l}\text { Player's game } \\
\text { preferences } \\
\text { (classification } \\
\text { from 1 to 5) }\end{array}$ & $\begin{array}{c}\text { Do not } \\
\text { like (1) }\end{array}$ & $\begin{array}{c}\text { Avoid } \\
\text { play (2) }\end{array}$ & $\begin{array}{c}\text { May } \\
\text { play (3) }\end{array}$ & $\begin{array}{c}\text { Like to } \\
\text { play (4) }\end{array}$ & $\begin{array}{c}\text { Like to play } \\
\text { a lot (5) }\end{array}$ \\
\hline Analog games & 0 & 0 & 1 & 4 & 1 \\
Sports & 0 & 0 & 1 & 1 & 4 \\
Digital games & 0 & 0 & 1 & 3 & 2 \\
Traditional games & 0 & 0 & 3 & 3 & 0 \\
\hline
\end{tabular}

\section{DATA COLLECTION}

The quantitative direct data was collected with inquiries before and after the games. The observation was done by the facilitator and recorded in a small report during game play, which was useful to the debriefing process.

Six students participated in the whole gaming session $(n=$ 6). The inquiries had yes/no questions and a 5-point Likert scale to measure preferences and perceptions from players. In Table 2, the players' game preferences are shown, highlighting the strongest preference for digital games and a massive appreciation of sports. Although a small number of players participated in the experiment, modern board games are usually played from 2 to 6 players (Woods, 2012; Rogerson and Gibbs, 2018). This type of small group is common in focus groups and other group working and collaboration techniques (Bishop, 2015).

Only one student answered saying that he had never participated in a learning or training session with games. Half of the students ignored the existence of modern board games, but they admitted playing games at least once per week. One player admitted playing every day, and one several times per day. Just one of the students played once per month. We can say the students were interested in games and played regularly.

Table 3 reveals the low levels of anxiety and frustration and the high levels of immersion, motivation, and fun felt during gameplay. Students also highlighted their ability to be flexible and adapt themselves to the game and other players' interactions, considering also that the level of challenge was recorded as high although the difficulty was average. The observation from the facilitator corroborates these perceptions.

Concerning the serious game effects, players considered the experience to be positive, referring to the seriousness of game applications, skill and knowledge testing, surprise, and the fun side of the games played. Only when asked if analog games could perform better than digital games as learning experiences and simulations did the answers reveal values apart from 4 ("a lot") to 5 ("totally/always") although 4 of the students considered that an analog game could be "totally/always" better than digital games to fulfill the objective of implementing a collaborative planning playable process. This may be surprising and may be biased because the students answered just after playing analog games. All this data is available in Table 4.

The inquiries before and after the games had one recurrent question: "How would you classify the learning and simulation 
TABLE 3 | Experiences and perceptions during game play of the gaming session.

\begin{tabular}{lccccc}
\hline $\begin{array}{l}\text { Experiences and } \\
\text { perceptions during } \\
\text { gameplay (classification } \\
\text { from 1 to 5) }\end{array}$ & $\begin{array}{c}\text { Nothing } \\
\text { (1) }\end{array}$ & $\begin{array}{c}\text { A bit } \\
\text { (2) }\end{array}$ & $\begin{array}{c}\text { Moderately A lot } \\
\text { (3) }\end{array}$ & $\begin{array}{c}\text { Totally } \\
\text { (4) }\end{array}$ & (5) \\
\hline Fun & & & & & \\
Difficulty & 0 & 0 & 0 & 2 & 4 \\
Immersion & 0 & 1 & 3 & 1 & 1 \\
Challenge & 0 & 0 & 0 & 3 & 3 \\
Anxiety & 0 & 0 & 2 & 1 & 3 \\
Adaptation ability & 1 & 3 & 2 & 0 & 0 \\
Surprise & 0 & 0 & 1 & 4 & 1 \\
Empathy among players & 0 & 0 & 2 & 2 & 2 \\
Frustration & 0 & 0 & 0 & 3 & 3 \\
Motivation & 3 & 3 & 0 & 0 & 0 \\
& 0 & 0 & 1 & 2 & 3
\end{tabular}

TABLE 4 | Questions about the serious game dimensions of the tested games.

\begin{tabular}{lccccc}
\hline $\begin{array}{l}\text { Questions about } \\
\text { the seriousness of } \\
\text { the games and } \\
\text { future applications } \\
\text { (classification 1 to 5) }\end{array}$ & $\begin{array}{c}\text { Nothing/ } \\
\text { No (1) }\end{array}$ & $\begin{array}{c}\text { A bit } \\
\text { (2) }\end{array}$ & $\begin{array}{c}\text { Moderately A lot } \\
\text { (3) }\end{array}$ & $\begin{array}{c}\text { Totally/ } \\
\text { always (5) }\end{array}$ \\
\hline $\begin{array}{l}\text { It was possible to test skill } \\
\text { and knowledge in the } \\
\text { game? }\end{array}$ & 0 & 0 & 0 & 3 & 3 \\
$\begin{array}{l}\text { Games could be applied to } \\
\text { other contexts and cases? }\end{array}$ & 0 & 0 & 0 & 2 & 4 \\
$\begin{array}{l}\text { Games fulfilled the serious } \\
\text { objectives? }\end{array}$ & 0 & 0 & 0 & 3 & 3 \\
$\begin{array}{l}\text { Would you play these } \\
\text { games just for fun? }\end{array}$ & 0 & 0 & 0 & 2 & 4 \\
$\begin{array}{l}\text { Were you surprised with the } \\
\text { game approach? }\end{array}$ & 0 & 0 & 0 & 2 & 4 \\
$\begin{array}{l}\text { Analog games can provide } \\
\text { better experiences and } \\
\text { simulations solutions than } \\
\text { digital games? }\end{array}$ & 0 & 0 & & & \\
\hline
\end{tabular}

potential of games?" The results are expressed in Table 4. Four players improved their perception of the potential of serious uses of games for learning and training to the maximum classification.

\section{RESULTS DISCUSSION}

\section{Board Game Results}

The first game established the communication and required empathy that helped players passing to the negotiation and cocreating of the second game although it was a competitive game played in teams: spy vs. all other players (see Figure 2). Players wanted to play more; however, the second game needed more time and only $2 \mathrm{~h}$ were available.

Players cooperatively played the second game (see Figure 3). Each player received 3 money units, and Table 1 was visible to all players during gameplay. Individual turns happened in a clockwise sequence without the possibility to pass because the city should continue to grow. This rule intended to address the thematic objective of sustainable urban growth. The map served as guidance, but it was not mandatory to follow the road systems although the river and hills should be considered. Nevertheless, players felt influenced by the represented morphologies.

The 6 players played a total of 30 turns, each one taking 5 turns. In the game, they used (see Figure 4)

- 10 housing cubes (green);

- 8 commercial/services cubes (yellow);

- 3 industries (black);

- 3 green parks (green token);

- 1 school (blue cube);

- 1 police office (red cube);

- 1 hospital (tall blue building);

- 3 public transport lines.

These options resulted in an income to the city budget of 75 money units, considering the contribution from the commercial/services and industry cubes, all taken to the maximum revenue capacity, represented by the 6 face-value dice at the top of each cube (see Figure 4). Each time a player proposed to use the common city budget, a vote was called. Only one time was the voting negative because players previously discussed each vote. All the used buildings that reduced pollution and negative social impacts cost 87 money units in total. Although the players' decisions produced only 75 units of revenue, they used their personal money to help build those facilities. In the end, only 2 players remained with some personal money: one player with 1 money unit and another with 2. The city budget had 3 money units remaining. However, at the end of the game, 2 cubes representing pollution and negative social impacts persisted on the board. All the other cubes were removed but put near the components that reduced them, so players could keep track of the ones remaining and the capacity of the buildings/components to absorb negative impacts.

During the second game, students started to do some parallel role-play, creating a narrative for the housing zones. Players naturally started to go beyond the symbology and meaning of the components as expected in the DPE adapted model (see Figure 1). For example, the housing zone near the hospital, between the 3 parks and with a direct public transport line, was considered to be the expensive habitational zone of the city, and the one most to the right was the poorer area, where residents lived packed together and in the periphery (see Figure 4).

\section{Inquiries and Observation Results}

Players enjoyed the games (see Table 3) with low levels of anxiety, low frustration, and high levels of fun and motivation. Players wanted to continue playing, but there was no more time available. Their opinion about the potential of learning and simulations though games increased greatly at the end of the experiment (see Table 5). When trying to make some correlation, although the data is small $(n=6)$, the correlation between the preference for digital games and the perception of the added value of analog games over digital games $(0,56)$ is higher than the correlation 
TABLE 5 | Players perceptions about the potential of serious games.

\begin{tabular}{lccccc}
\hline $\begin{array}{l}\text { Players classification } \\
\text { the learning and } \\
\text { simulation potential } \\
\text { of games }\end{array}$ & $\begin{array}{c}\text { Nothing/ } \\
\text { No (1) }\end{array}$ & $\begin{array}{c}\text { A bit } \\
\text { (2) }\end{array}$ & $\begin{array}{c}\text { Moderately A lot } \\
\text { (3) }\end{array}$ & $\begin{array}{c}\text { Totally/ } \\
\text { (4) } \\
\text { always } \\
\text { (5) }\end{array}$ \\
\hline $\begin{array}{l}\text { Before the games } \\
\text { After the games }\end{array}$ & 0 & 0 & 0 & 5 & 1 \\
\hline
\end{tabular}

between the preference for analog games and the perception of the added value of board games over digital games $(0,17)$.

Through direct observation by the facilitator, some information was gathered in the observation notes about the experience. Players had little doubts about the games during gameplay, and those players who understood the game faster explained to other players the decisions they could make and the expected impacts on the game systems. This rule enforcing helped the collaboration process. These interactions allowed the fast pace of the game with little downtime, and due to the small number of participators, all players were engaged in playing the game. No reports of smartphone use or parallel talk were reported during game play $(2 \mathrm{~h})$.

\section{CONCLUSIONS}

The application and adaptation of the DPE framework helped to define the game session, the objectives for each game, and their relationships. Also, considering the role of the facilitator as an actor who knew the design objectives, helped players to participate in the game experience and to achieve the desired goals by themselves. The implemented design, in its multiple flows, created a game play that players enjoyed. The game results (see Figures 2, 4) express the debate about the urban map in the first game and the collaborative decision making that generated a coherent new urban model during the second game.

Players entered the game without knowing what to expect. They felt engaged, considering the results from the inquiries (see Table 3), in loco observations and the result of the city model (see Figures 4, 5). The first game contributed to understanding and share knowledge about the territory, empowering students through the question mechanic. The second game allowed students to discuss and implement, in a collaborative way, general guidelines and ideas to plan the city, receiving realtime feedback from the chain/cascading mechanics of the cube placement. No downtime between plays and turns was registered. The decisions were proposed by the active player, but all others participated with their opinions and easily contributed by giving their money to build expensive buildings and facilities. There was no record of non-collaboration or game disengagement in general (only one call to vote in nine failed), enforcing the notion that a city model can be planned collaboratively with few rules despite it being important to generate the debate and the consensus-building to activate and profit from the cube placement and cascading effects in the city economy.
The debriefing moment was fast and easily supported by the second game results, materialized in the game model itself, which acted as examples to remember decisions and the process of urban growth. By playing the second game, players expressed the potential for this game system to help deliver general guidelines to plan the urban space. This model helped the facilitator to address the subjects of sustainable growth and the urban interactions of land use, facilities, and infrastructure. The discussion with students happened through the game itself as mentioned with moments of collective reflection and decisions that allowed the continual growth of the city, generating income, and progressively reducing negative outcomes through gameplay. In the final debriefing, the students agreed that they could have reduced all the negative outcomes if they did not focus mainly on the income although only two negative cubes remained on the map (see Figures 4, 5). This was used during debriefing as a metaphor for the prevalence of efficiency models that mainly promote the economic outputs in most plans. The game system engaged the player to the point that narratives emerged naturally. Players enjoyed and established meaning for the game dynamics, which is proof of success for general game design objectives (Salen and Zimmerman, 2004) and, in this case, of a serious game (Winn, 2009) to promote participation in a playable planning process. It can be concluded that the game achieved its serious objectives because players played in collaboration, discussing every play from the first and only collectively rejecting action. The objectives of sustainability were also reached due to the existence of only two negative cubes remaining on the board while having a positive money surplus for the city's common budget.

This experiment showed it is feasible to implement a serious game experience to simulate a simple urban model, using modern board game components and mechanics to establish collaborative planning, following the DPE adapted framework. The use of the printed Google Map and the simple spreadsheet is flexible enough to simulate simple planning game approaches and compliant with modern board game mechanics. Students did not know the lecture would be done with games; they just knew it was about collaborative planning. This promises to be an approach with the potential for usage in other planning processes, profiting from the innovation and flexibility of these new game designs and the continuous development of serious game frameworks.

\section{GAPS AND FUTURE DEVELOPMENTS}

Although the second game seems balanced with a tight economy between the costs of the actions and their positive and negative outputs, more testing should be done to truly balance it in all situations. Nonetheless, the results seem promising, showing that applying innovative mechanics and other design elements from modern board games, supported by a simple spreadsheet table, can help players understand the economy of the game in a fun way. The game system can be played over a map, opening possible new adaptations to other, different, urban realities.

With one play, it was possible to plan a new urban solution, but the continuous plays of the game by the same players 
improved the relationship with cost and effects, just like the knowledge of the played city map.

The application of the DPE framework proved to be useful, and the possibility of adaptation opens new paths for future uses of analog serious games. This approach provides more tangible design support to non-game designers who may want to start a serious game-planning process.

Some difficulties in understanding the proximity effects during game play were felt. In future tests, some transparent reference grid with squares or hexagons should be used over the map, assisting in reading the neighboring land units, the shapes, places to put the cubes, and the distances between all game components. The design of war games and Eurogames maps, with their hexagonal shapes, could help improve this. The capacity of the public transport lines should also be defined and marked on the board, for example, their precise length.

The effects of over-concentration should also be considered and produce extra negative outputs. This was obvious to players through the narrative they created. Players also understood the effects of the heavy industry location. They used the public transport lines to put it away from housing but connected to it and to the commercial/services to generate the expected income.

The tracking of income through the dice was efficient, easily related to the source of the revenue due to the color of the cubes above them although limiting it to 6 units (the pips of the D6 dice). In the future, other types of dice can be used, easily increasing the pip value to 20 if necessary (with the D20 used in role-playing games).

In future tests, some formal role play should be introduced because players showed a natural will to establish narratives associated with the city morphology. This could transform the game into a semi-cooperative game, having different roles and some hidden victory conditions to every player, simulating in this way stakeholders' and citizens' behavior as well as hidden agendas in a participative and collaborative planning process. This could be easily done by giving different profile cards to each

\section{REFERENCES}

Allmendinger, P. (2017). Planning theory. London: Macmillan International Higher Education. doi: 10.1057/978-0-230-38004-2

Alspach, T. (2012). Suburbia. Board game. Bézier games.

Ampatzidou, C., Gugerell, K., Constantinescu, T., Devisch, O., Jauschneg, M., and Ber-ger, M. (2018). All work and no play? Facilitating serious games and gamified applications in participatory urban planning and governance. Urban Plan. 3, 34-46. doi: 10.17645/up.v3i1.1261

Arnaudo, M. (2018). Storytelling in the Modern Board Game: Narrative Trends From the Late 1960s to Today. Jefferson, MO: McFarland.

Bishop, J. (2015). The Craft of Collaborative Planning: People Working Together to Shape Creative and Sustainable Places. New york, NY: Routledge. doi: 10.4324/9781315732848

Booth, P. (2015). Game Play: Paratextuality in Contemporary Board Games. New York, NY: Blooms-bury.

Brand, I., and Brand, M. (2017). Rajas of the Ganges. Huch!.

Castells, M. (1996). "The rise of the network society" in The Information Age: Economy, society and culture. Vol 1. Cambridge, MA: Blackwell. player. More testing with more students and other city maps is also important for future developments that now are possible following this approach.

Another possible development consists of using digital technology and devices to read the game components' disposition and automatically generate information about the component's interactions.

\section{DATA AVAILABILITY STATEMENT}

The raw data supporting the conclusions of this article will be made available by the authors, without undue reservation.

\section{ETHICS STATEMENT}

Ethical review and approval was not required for the study on human participants in accordance with the local legislation and institutional requirements. The patients/participants provided their written informed consent to participate in this study.

\section{AUTHOR CONTRIBUTIONS}

The author confirms being the sole contributor of this work and has approved it for publication.

\section{FUNDING}

The author would like to thank Fundação para a Ciência e a Tecnologia (FCT), the Portuguese funding agency that supported this research under the grant PD/BD/146491/2019.

\section{ACKNOWLEDGMENTS}

The author would like to thank Professor João Pedro Silva for revising the paper and allowing the experimental class and Professor António Pais Antunes for being the author's Ph.D. thesis supervisor.

Castronova, E., and Knowles, I. (2015). Modding board games into serious games: the case of Climate Policy. Int. J Serious Games 2, 41-62.

Crookall, D. (2010). Serious games, debriefing, and simulation/gaming as a discipline. Simul. Gaming 41, 898-920. doi: 10.1177/10468781103 90784

Donovan, T. (2017). It's All a Game: The History of Board Games from Monopoly to Settlers of Catan. New York, NY: St. Martin's Press.

D'Orey, G., Soledade, P., and Sentieiro, N. (2014). Panamax. Board game. MESAboardgames.

Dörner, R., Göbel, S., Effelsberg, W., and Wiemeyer, J., (eds.). (2016). Serious Games: Foundations, Concepts and Practice. Springer. doi: 10.1007/978-3-319-40612-1

Engelstein, J., and Shalev, I. (2019). Building Blocks of Tabletop Game Design: An Encyclopedia of Mechanisms. London: Routledge; CRC Press. doi: 10.1201/978042943 0701

Gaarder, H. (2019). Villagers. Board game. Sinister Fish Games.

Giddens, A. (1984). The Constitution of Society. Berkeley, CA: University of California Press. 
Habermas, J. (1981). The Theory of Communicative Action: Reason and the Rationalization of Society. Boston, MA: Beacon Press.

Hayashi, H. (2009). String Railway. Board game. Okazu brand.

Healey, P. (1997). Collaborative Planning: Shaping Places in Fragmented Societies. New York, NY: Macmillan International Higher Education. doi: 10.1007/978-1-349-25538-2

Innes, J. E., and Booher, D. E. (1996). Consensus building as role playing and bricolage: toward a theory of collaborative planning. J. Am. Plan. Assoc. 66, 9-26. doi: 10.1080/01944369908976031

Innes, J. E., and Booher, D. E. (2018). Planning with Complexity: An Introduction to Collaborative Rationality for Public Policy. London, New York, NY: Routledge. doi: 10.4324/9781315147949

Järvinen, A. (2008). Games Without Frontiers: Theories and Methods for Game Studies and Design. Tampere: Tampere University Press.

Lederman, L. C. (1992). Debriefing: toward a systematic assessment of theory and practice. Simul. gaming 23, 145-160. doi: 10.1177/10468781922 32003

Margerum, R. D. (2002). Collaborative planning: building consensus and building a distinct model for practice. J. plan. educ. res. 21, 237-253. doi: 10.1177/0739456X0202100302

Mayer, I., Bekebrede, G., Harteveld, C., Warmelink, H., Zhou, Q., van Ruijven, T., et al. (2014). The research and evaluation of serious games: toward a comprehensive methodology. Br. J. Educ. Tech. 45, 502-527. doi: 10.1111/bjet.12067

Michael, D., and Chen, S. (2006). Serious Games: Games that Educate, Train, and Inform. Boston, MA: Thomson Course Technology.

Parlett, D. S. (2018). Parlett's History of Board Games: the Updated Edition of The Ox-ford History of Board Games. Bratt: Echo Point Books and Media.

Portugali, J. (2016). "What makes cities complex?" in Complexity, Cognition, Urban Planning and Design (Cham: Springer), 3-19. doi: 10.1007/978-3-319-32653-5_1

Rogerson, M. J., and Gibbs, M. (2018). Finding time for tabletop: board game play and parenting. Games Cult. 13, 280-300. doi: 10.1177/15554120166 56324

Rogerson, M. J., Gibbs, M. R., and Smith, W. (2018). “Cooperating to compete: the mutuality of cooperation and competition in boardgame play," in proceedings of the 2018 CHI Conference on Human Factors in Computing Systems (Montreal, QC). doi: 10.1145/3173574.3173767

Rosenberg, U. (2018). Agricola: Farmers of the Moor. Board game. Lookout games.
Salen, K., and Zimmerman, E. (2004). Rules of Play: Game Design Fundamentals. London, UK: MIT Press.

Sicart, M. (2008). Defining game mechanics. Game Studies, 8. Available online at: http://gamestudies.org/0802/articles/sicart?viewType=Print\&viewClass=Print

Sousa, M., and Bernardo, E. (2019). "Back in the game," In International Conference on Videogame Sciences and Arts (Cham: Springer), 72-85. doi: 10.1007/978-3-030-37983-4_6

Tan, E. (2016). "The evolution of city gaming," in Complexity, Cognition, Urban Planning and Design. In Post-Proceedings of the 2 nd Delft International Conference, eds J. Portugali, and E. Stolk (Springer). doi: 10.1007/978-3-319-32653-5_15

Tan, E., and Portugali, J. (2012). “The responsive city design game," in Complexity Theories of Cities have come of Age (Berlin; Heidelberg: Springer), 369-390. doi: 10.1007/978-3-642-24544-2_20

Taylor, N. (1998). Urban Planning Theory Since 1945. London, UK: Sage.

Ushan, S. (2014). Spyfall. Board game. Hobby World.

Viard, A. (2014). Town Centre. Board game. LudiCreations.

Winn, B. M. (2009). “The design, play, and experience framework," in Handbook of Research on Effective Electronic Gaming in Education (IGI Global), 1010-1024. doi: 10.4018/978-1-59904-808-6.ch058

Woods, S. (2012). Eurogames: The Design, Culture and Play of Modern European Board Games. Jefferson, MO: McFarland.

Xu, Y., Barba, E., Radu, I., Gandy, M., and MacIntyre, B. (2011). "Chores are fun: understanding social play in board games for digital tabletop game design," in DiGRA Conference.

Zagal, J. P., Rick, J., and Hsi, I. (2006). Collaborative games: lessons learned from board games. Simul. Gaming 37, 24-40. doi: 10.1177/1046878105282279

Conflict of Interest: The author declares that the research was conducted in the absence of any commercial or financial relationships that could be construed as a potential conflict of interest.

Copyright (c) 2020 Sousa. This is an open-access article distributed under the terms of the Creative Commons Attribution License (CC BY). The use, distribution or reproduction in other forums is permitted, provided the original author(s) and the copyright owner(s) are credited and that the original publication in this journal is cited, in accordance with accepted academic practice. No use, distribution or reproduction is permitted which does not comply with these terms. 